\title{
Partituras imagéticas do corpo: um experimento transdisciplinar em neurociência e arte contemporânea
}

\author{
Imagetic partitures of the body: a transdisciplinar \\ experimente in neuroscience and contemporary art
}

\section{Dandara Dantas}

Programa de Pós-graduação em História das Ciências e das Técnicas e Epistemologia (HCTE), Universidade Federal do Rio de Janeiro (UFRJ)

dantas.dandara@gmail.com

orcid.org/0000-0002-6879-7701

\section{Maira Fróes}

Programa de Pós-graduação em História das Ciências e das Técnicas e Epistemologia (HCTE), Universidade Federal do Rio de Janeiro (UFRJ)

froes.maira@gmail.com

orcid.org/0000-0002-3690-5245

Resumo. O objetivo deste artigo é proporcionar uma reflexão acerca de um experimento que mistura uma poética contemporânea com metodologias e pensamentos em neurociência na produção de processos e objetos híbridos. $\mathrm{O}$ trabalho pregresso que suscitou esta pesquisa consistiu em uma poética de tradução de informações musicais em imagens por meio de uma remodelagem gráfica de partituras de piano. Posteriormente, em um laboratório de neurociências, em vez de informações musicais, essa poética recebeu como input dados de condutância de pele, relativos à engajamento emocional, com o fim de desenvolver um processo gerador de novas visualizações para dados de emoção. Este artigo se propõe a analisar esse experimento de acoplamento processual e seus resultados transdisciplinares.

Palavras-chave: Imagem. Música. Neuroepistemologia. 
Abstract. The aim of this article is to provide a reflection on an experiment that mixes contemporary poetics with methodologies and thoughts in neuroscience in the production of hybrid objects and processes. The previous work that gave rise to this research consisted of a poetics of translating musical information into images through a graphic remodeling of piano scores. Later, in a neuroscience laboratory, instead of musical information, this poetics received skin conductance data, related to emotional engagement, in order to develop a process that generates new visualizations for emotion data. This article proposes to analyze this process coupling experiment and its transdisciplinary results.

Keywords: Image. Music. Neuroepistemology.

Recebido: 01/10/2017. Aceito: 27/10/2017. Publicado: 06/11/2017

\section{Introdução}

Esse artigo consiste em um recorte da qualificação de minha pesquisa de doutorado teórico-prática "Partituras Imagéticas trans formadas" que tem como objetivo pensar e criar objetos transdisciplinares a partir da aplicação do método artsci na poética contemporânea intitulada "Partituras imagéticas".

A partir da aplicação desse método, que será apresentado adiante, no Laboratório de Métodos Avançados e Epistemologia/LAMAE do Programa de Pós-graduação em História das Ciências e das Técnicas e Epistemologia/HCTE da UFRJ, coordenado pela professora e orientadora desta pesquisa Maira Fróes, obtivamos um primeiro experimento dessa interface processual, que nos permitiu observar e analisar diferentes níveis de imbricação entre arte e ciência, o qual intitulamos Partituras Imagéticas do Corpo.

Junto da neurocientista Cecilia Hedin e do musicista contemporâneo Eufrasio Prates, tivemos a chance de submeter ao edital da Internatinal Brain Research Organization (IBRO) uma proposta de extensão desse primeiro experimento no evento que chamamos Conversando sobre o código neural na interface arte e ciência. O objetivo foi abrir nosso processo em uma exposição laboratório, um espaço lúdico de experimentação e conversa com o público acadêmico e leigo, para além das fronteiras da universidade. Vencedores do edital, levamos para a Galeria Modernistas (Santa Teresa, Rio) o acervo de objetos e experimentos desenvolvidos até esta etapa da pesquisa: quadros-esculturas, móbiles, instalações, uma performance interativa e, sobretudo, as Partituras Imagéticas do corpo para discutir sobre modelos científicos a partir da poética contemporânea Partituras Imagéticas.

De volta ao laboratório, foi possível refletir sobre os resultados práticos, conceituais e epistemológicos dessa experiência de abertura do processo para um público diverso, aprimorar pesquisa e fortalecer o método artsci. Essas são as reflexões que pretendemos desenvolver neste artigo.

Partituras imagéticas: uma poética interdisciplinar em um laboratório de neurociências 
No âmbito do mestrado, tive a oportunidade de confrontar texto e imagem por meio da representação musical. Esta pesquisa até então intitulada "Partituras Imagéticas", que chamaremos de poética PI, nascia no território das artes visuais contemporâneas, à luz da análise do filósofo tcheco Vilém Flusser (2007) acerca das linhas textuais e superfícies imagéticas no que tange suas diferenças de (de)codificações.

O então experimento PI consistiu em uma poética de tradução de música em imagem a partir da problematização da linguagem hermética textual das partituras musicais. Tratouse de uma remodelagem na estrutura da partitura de piano com o objetivo de subverter seu propósito textual, informativo, linear e simbólico, e dar lugar à um novo arranjo visual com intenção de imagem: não linear e predominantemente estético e subjetivo.

As escolhas visuais dessa remodelagem partiram de uma analogia visual com minha experiência musical, principalmente, no que se refere à sensação permanente da pausa e à percepção de tempo não linear tal como ocorre no nível imagético. Com isso, obteve-se uma nova visualização da música: circular, sem início, meio ou fim, e sem o intuito de ser objetivamente decodificada. $\mathrm{O}$ objetivo era criar uma representação imagética da fruição musical, suprimindo a carga simbólica da representação musical em forma de texto. As superfícies resultantes, carregadas de dados musicais, foram redimensionadas para imagens virtuais, incluindo projetos de performances e protótipos de esculturas.

Ao apresentar esta poética de imagem e música à neurocientista Maira Fróes, levantouse as seguintes questões: Poderiam as Partituras Imagéticas revelar estruturas orgânicas fisiológicas? Qual seria a visualização resultante da inserção de dados de emoção no processamento de Partituras Imagéticas/PI?

Tais perguntas se tornaram questões endereçáveis tanto às neurociências quanto às artes e nos motivou a experimentar a utilização de dados de condutância de pele na poética Partituras Imagéticas/PI e, juntas, analisar este processo híbrido e seus resultados.

Uma perspectiva sobre o método artsci na imbricação entre neurociência e arte contemporânea, na premissa de que a arte seja a maior ferramenta tecnológica disparadora da imaginação humana, e ao considerar justamente que a imaginação sirva tanto às artes quanto às ciências, a pesquisadora Maira Fróes defende a introdução das artes contemporâneas no cotidiano dos laboratórios científicos:

\footnotetext{
Tendo as artes optimizado a imaginação em graus de liberdade sem precedentes, pois não necessariamente comprometida com arcabouços lógicos pré-moldados como os obedecidos dentro da prática e narrativa científicas, seu processo criativo deveria ser de grande interesse para a ciência, sobretudo quando se considera o quanto a ciência é alimentada e potencializada por perspectivas e modelos interpretativos essencialmente dependentes de criatividade e imaginação (FRÓES, 2015).
}

Além de considerar a relevância do estímulo à imaginação nas ciências através da arte, para Fróes (2011) e colaboradores, a própria figura do cientista é também alargada no sentido de considerar suas emoções e subjetividades no seu fazer científico. Para Fróes, por dentro da figura do cientista, existe um sujeito sensível, pleno em afeto e imaginação, recursos humanos rejeitados na visão hegemônica da ciência contemporânea ocidental, 
mas que, conforme seu grupo vem defendendo e demonstrando nos últimos anos, deveriam ser estimulados na produção das ciências.

Para experimentar a aplicação de suas premissas, Fróes realizou sessões de discussões entre artistas e cientistas, disparadas por obras de arte no Instituto Inhotim de Arte contemporânea. A finalidade era estruturar um formato não hierárquico de troca e produção de conhecimento envolvendo esses três territórios: artistas, cientistas e obras de arte. Após esses experimentos por ela referidos como "triangulações artsci", Fróes afirma que essa problematização híbrida provocada pela experiência estética é capaz de transformar o pensamento científico convencional.

Apesar de as ciências trabalharem com modelos universais e as artes com poéticas subjetivas, o método artsci aposta na possibilidade de migração de conhecimento do campo artístico para o científico através de associações conceituais, metáforas e isomorfismos entre padrões de ambas as áreas. Mais do que a emergência de uma ciência sensível, em que se reconhece a presença de realidades subjetivas, acredita-se que a abstração e o conhecimento das artes possam potencializar e antecipar o conhecimento científico.

Nesse contexto, surgia então o convite inusitado para experimentar a poética PI como potencial revelador de novos padrões nos dados científicos. Nascia assim o embrião da tese, disparada por uma residência artística em um laboratório de neuroepistemologia experimental.

Essa investigação encontrou inicialmente apoio na neuroestética, corrente contemporânea criada pelo neurocientista turco Semir Zeki (2014), defensora de que as investigações artísticas e científicas têm questões em comum, apenas buscam caminhos diferentes para respondê-las. No entanto, apesar de as perguntas que motivam a produção de conhecimento e de expressão humana em artes e ciências serem semelhantes e já reconhecidas em áreas como a neuroestética e correntes na arte contemporânea, existe uma desconexão entre essas áreas, sobretudo, em termos de processo.

A arte pode ser objeto de estudos das ciências assim como dados e ferramentas científicas costumam já ser utilizados nas artes, porém, em ambas as áreas, é recorrente observar que seus arcabouços teóricos, que sustentam seus processos e reflexões, continuam sem sofrer interferência da chamada outra área. As zonas de conforto epistemológicas permanecem protegidas contra qualquer alteração nas suas bases teóricas. Os resultados são diversos, porém os pensamentos que envolvem os processos que lhes resultam continuam isolados.

Mas e se esses processos pudessem se misturar e se fortalecer mutuamente? Existiriam metodologias acopláveis capazes de contribuir tanto para as artes quanto para as ciências?

A hipótese levantada por esta pesquisa, portanto, é uma aposta na possibilidade de uma poética artística contemporânea desvelar, através de isomorfismos, estruturas de ordem neurofisiológicas que os sistemas de análise científicos não estão aparelhados conceitual e tecnologicamente para enxergar. Acreditando que a imbricação entre poéticas artísticas e processos científicos possam contribuir para ambas as áreas, o objetivo geral desta investigação tornou-se a aplicação do método artsci na poética Partituras Imagéticas para 
desenvolver objetos híbridos, em uma imbricação de processos entre neurociências e artes contemporâneas.

Além de produzir conhecimento nos macro campos da arte e da ciência sob novas perspectivas, uma consequência imediata desta investigação é a discussão epistemológica em torno da visão da neuroestética em relação à arte, uma base para a pesquisa inicialmente, que ao longo da investigação, começou a ser problematizada.

A neuroestética busca entender os mecanismos neurais que permitem ao ser humano experimentar a beleza (ZEKI, 2014). Investiga, portanto, o impacto da obra sobre o espectador com interesse no resultado estético da arte tendo como parâmetro conceitos como "o belo". Assim, apesar de consistir em um ramo contemporâneo da neurociência, utiliza-se de conceitos tradicionais da arte, hoje já desconsiderados pela arte contemporânea.

A relevância desta investigação está, portanto, em propor uma atualização da neuroestética segundo o pensamento, também contemporâneo, da arte, sobretudo, ao considerar a obra de arte como processo.

O trabalho se torna relevante, ainda, ao considerarmos o papel social do artista contemporâneo segundo o pensamento de Vilém Flusser (2008). De acordo com o filósofo tcheco, o artista de hoje deve subverter os meios de criação disponíveis, o computador e tecnologias relacionadas, na busca deliberada pelo imprevisível. Para ele, os que operam os programas sem conhecer seus processos seriam apenas seus funcionários. Nesse sentido, o artista deveria ser como um jogador, que joga um jogo contrário ao estabelecido, com o fim de subverter automatizações em busca do imprevisto, da informação nova. Nessa perspectiva, os processos e tecnologias utilizados na neurociência podem ser considerados um território de trabalho e subversão para o artista contemporâneo.

\section{Partituras imagéticas do corpo}

O primeiro experimento intitulado Partituras Imagéticas do corpo tinha como fim criar imagens e sons da poética Partituras Imagéticas (PI) a partir de dados de condutância de pele $^{1}$. Partiríamos dessa primeira etapa de medição de dados para a circularização do tempo e geraríamos gráficos equivalentes às partituras imagéticas (resultantes do experimento pregresso de tradução de partituras musicais em imagens).

No entanto, nos deparamos com a necessidade de dar um passo atrás, antes mesmo de medir e trabalhar os dados gerados por esta experimentação, pois as seguintes questões axiais encontravam-se em aberto: como parametrizar dados originais e/ou atributos biofísicos calculados a partir do processamento destes dados dentro de um universo de

\footnotetext{
${ }^{1}$ Medidas elétricas obtidas a diminutos intervalos de tempo através de um sensor galvânico $(Q$ Sensor, Affectiva) localizado na superfície da pele - parte interna do pulso -, proporcionais à dinâmica de produção de suor pelo voluntário.
} 
atributos sonoros/musicais? Como relacioná-los à estrutura visual das Partituras Imagéticas?

Toda essa lógica de tradução e equivalências estava por ser construída dentro de um universo de partida que não mais consistia de partituras musicais, mas de traçados fisiológicos. Por exemplo, considerando que o modelo poético PI traduz informações musicais, como notas nas claves de sol e fá, foi preciso decidir que dados/informações coletados pelo Q sensor seriam traduzidos como esta ou aquela função sonora/musical, e por quê. É o que Manovich (2004) chama de escolhas de mapeamento justamente para não estabelecer relações visuais arbitrárias, o que enfraqueceria a metodologia. Quais seriam então as escolhas para dar visualidade aos dados, relacionando-os a informações musicais do modelo PI?

Para isso, foi preciso estabelecer uma ponte entre atributos das medidas de condutância da pele e atributos musicais a partir de discussões em várias rodadas sobre cognição e fruição musical, tanto do ponto de vista poético subjetivo quanto do ponto de vista científico, respectivamente, levantados por mim, a artista criadora da PI e, Maira, neurocientista e orientadora desta pesquisa.

Da proposta preliminar de um sistema de chaveamento de informações de condutância de pele em uma poética imagético-musical, seguimos para a próxima etapa: preparar os dados para servir de input nas Partituras Imagéticas. Maira sistematizou a parametrização dos dados através de cálculos de derivadas e filtros matemáticos, contando com recursos algorítmicos desenvolvidos pelos colaboradores: Murilo Moura, estudante de Iniciação Científica do LAMAE (HCTE/UFRJ) e Estevão Ferrão, engenheiro do Laboratório de Acústica e Vibrações/LAVI do Instituto Alberto Luiz Coimbra de Pós-Graduação e Pesquisa de Engenharia/COPPE (UFRJ). Após essa etapa, os dados foram estruturados para coincidir com a estrutura circular da poética PI.

Considerando o trabalho dessa equipe interdisciplinar, pode-se dizer que a metodologia do experimento contou com ferramentas e processos em artes e ciências. Notamos também que a interdisciplinaridade de uma etapa atuava sobre resultados da etapa anterior, também de natureza hídrida. Esse hibridismo esteve presente, portanto, de forma reiterada em todos os momentos do experimento: desde a co-problematização do objeto (chaveamento dos dados de condutância de pele com os parâmetros sonoros/musicais), passando pelo processo (utilização de metodologias e ferramentas em artes e ciências) e finalmente também na análise de resultado (pela dupla artista/neurocientista), representado no nível 3, o que nos possibilitou enxergar e elaborar um sistema de três diferentes níveis de imbricação entre arte e ciência.

Considerando diferentes áreas do conhecimento, no contexto de um trabalho interdisciplinar, no nível 1, apenas dados seriam compartilhados entre as essas áreas. A problematização do objeto, metodologias, bibliografia e análise de resultados permanecem inalterados. No nível 2, um pouco mais aprofundado, além de dados, compartilham-se também informações entre as diferentes áreas, por meio de bibliografias 
e ferramentas, permitindo a geração de um resultado híbrido que, reconhecivelmente, contém partes de ambas as áreas.

No nível 3, a hibridização já teria início desde a problematização do objeto por diferentes áreas, de maneira conjunta. Em seguida, o objeto co-problematizado se desenvolve em um processo híbrido que inclui dados, ferramentas e bibliografia de diferentes áreas. Dessa maneira, os processos e os conhecimentos interferem-se entre si, se alteram, não mais se preservam enquanto áreas delimitadas, e produzem um resultado transdisciplinar, em que não se pode mais mensurar até onde está a influência clara de uma área ou outra, se instaura uma terceira ordem.

\section{Conclusões}

Ao considerar as sucessões de interferência de ambas as áreas (artes visuais e neurociências) ao longo das etapas, entendemos que não é mais possível delimitar as fronteiras entre arte e ciência no resultado final. Esses limites não estariam mais visíveis. O produto do experimento Partituras imagéticas do corpo vai além do híbrido, trata-se de um objeto transdisciplinar.

Esse pensamento fez estalar a hipótese inicial da tese, de que criaríamos objetos híbridos. A nova hipótese defendida por esta pesquisa é que, dependendo da extensão e profundidade de imbricação entre arte e ciência em um processo de pesquisa e produção de artefatos, pode-se criar objetos transdisciplinares, que estariam além da interface nítida entre arte e ciência.

\section{Financiamento}

O presente trabalho foi realizado com apoio do Conselho Nacional de Desenvolvimento Científico e Tecnológico (CNPq).

\section{Referências}

AGUIAR, A. A. de. Avaliação da microbiota bucal em pacientes sob uso crônico de penicilina e benzatina. 2009. Tese (Doutorado em Cardiologia) - Faculdade de Medicina, Universidade de São Paulo, São Paulo, 2009.

ALEXANDRESCU, D. T. Melanoma costs: a dynamic model comparing estimated overall costs of various clinical stages. Dermatology Online Journal, [s. 1.], v. 15, n. 11, p. 1, Nov. 2009. Disponível em:

http://dermatology.cdlib.org/1511/originals/melanoma_costs/alexandrescu.html. Acesso em: 3 nov. 2019.

BAUMAN, Z. Globalização: as consequências humanas. Rio de Janeiro: Jorge Zahar, 1999. 
BRASIL. [Constituição (1988)]. Constituição da República Federativa do Brasil de 1988. Brasília, DF: Presidência da República, [2016]. Disponível em:

http://www.planalto.gov.br/ccivil_03/Constituicao/Constituiçao.html. Acesso em: 1 jan. 2019.

BRAYNER, A. R. A.; MEDEIROS, C. B. Incorporação do tempo em SGBD orientado a objetos. In: SIMPÓSIO BRASILEIRO DE BANCO DE DADOS, 9., 1994, São Paulo. Anais [...]. São Paulo: USP, 1994. p. 16-29.

FRÓES, M. M. O Sonho de Descartes. In: SCIENTIARUM HISTÓRIA, 3, 2010, Rio de Janeiro. Livro de anais do Scientiarum História III, Rio de Janeiro: UFRJ,2010. Disponível em: http://www.hcte.ufrj.br/index.html?arq=scientiarum.htm\&flag=expand. Acesso em: 3 nov. 2019.

MOZART, W. A. Sinfonia n. 40 em sol menor: KV 550. Viena: Fiktionaler Verlag, 1778. 1 partitura.

ROMANO, G. Imagens da juventude na era moderna. In: LEVI, G.; SCHMIDT, J. (org.). História dos jovens 2: a época contemporânea. São Paulo: Companhia das Letras, 1996. p. 7-16. 